УДК 316.43

ББК 60.54

$10.17213 / 2075-2067-2021-1-70-76$

\title{
О РОЛИ СОЦИАЛЬНОЙ ИНФРАСТРУКТУРЫ \\ В ПРЕОДОЛЕНИИ СОЦИАЛЬНОЙ ЭКСКЛЮЗИИ СЕЛЬСКОЙ МОЛОДЕЖИ
}

\section{(C) 2021 г. М. А. Кужелев}

\section{Донской государственный технический университет, г. Ростов-на-Дону, Россия}

Цель исследования - дать анализ состояния сочиальной инфраструктуры российского села и ее роли в преодолении социальной эксклюзии сельских жителей, в особенности молодежи.

Поднимается вопрос об образе жизни молодых жителей села с точки зрения его структурных компонентов, дается разделение понятий «уровень жизни» и «качество жизни». В статье рассматривается сочиально-экономическое положение российского села, основанное на фактологических данных мониторинга, которые свидетельствуют о системных проблемах, препятствуюших повышению уровня качества жизни сельских жителей, в особенности молодежи как наименее защищенной части населения.

Методологической базой исследования являются соичокультурный, ресурсныий и адаптационный подходы в изучении образа жизни сельской молодежи.

В качестве результатов исследования приводятся аргументы в пользу устранения разницы уровня развития социально-экономической инфраструктуры города и села, что даст возможность в перспективе не только приостановить системный коллапс и деградацию российского села, но и неминуемо приведет к замедлению роста обезлюдевших сельских населенных пунктов и повышению их привлекательности. Особая роль отводится агитационной работе среди сельской молодежи по ее активному участию в различных социокультурных мероприятиях с иелью снижения риска сочиальной эксклюзии и более полной и успешной интеграџии данной сочиально-демографической группь в общество.

Ключевые слова: сельская молодежь; образ жизни; сочииальная эксклюзия; сочиальная инфраструктура.

\section{ABOUT THE ROLE OF SOCIAL INFRASTRUCTURE IN OVERCOMING SOCIAL EXCLUSION OF RURAL YOUTH}

\author{
(C) 2021 M. A. Kuzhelev
}

\section{Don State Technical University, Rostov-on-Don, Russia}

The purpose of the study is to analyze the state of the social infrastructure of the Russian countryside and its role in overcoming the social exclusion of rural residents, especially young people.

The question of the young villagers'way of life in terms of its structural components is raised and the separation of the concepts of «level of life» and "quality of life» is given. The article examines the socio-economic situation of the Russian countryside, based on factual monitoring data, which indicates the systemic problems that hinder the improvement of the quality of life of rural residents, especially young people, as the least protected part of the population. 
The methodological basis of the research is socio-cultural, resource-based and adaptation approaches in the study of the rural youth way of life.

As the results of the study, arguments in favor of eliminating the difference in the level of the socio-economic infrastructure development of the city and the village are given, what will make it possible not only to stop the systemic collapse and degradation of the Russian village in the future, but also inevitably lead to a slowdown in the growth of depopulated rural settlements and increase their attractiveness. A special role is given to agitation work among rural youth for their active participation in various socio-cultural events in order to reduce the risk of social exclusion and more complete and successful integration of this socio-demographic group into society.

Key words: rural youth; way of life; social exclusion; social infrastructure.

Введение. Авторы отечественных социологических исследований полагают, что сегодня ученые не пришли к единому взгляду на определение таких понятий, как «уровень жизни» и «качество жизни», а также «их операционализации через систему показателей. Зачастую они используются как взаимозависимые, а перечни показателей-индексов во многом совпадают» [3, с. 33]. Тем не менее, данные понятия выступают интегративными составляющими при описании «образа жизни» представителя той или иной социальной группы. Категория «уровень жизни» формируется условиями в сфере потребления и определяется через показатели общего социально-экономического благосостояния жителей того или иного региона (уровень их дохода, потребления товаров и услуг, жилищные условия, услуги образования), а понятие «качество жизни» выражается как уровнем жизни, так и уровнем личного социального благополучия, психологического самочувствия.

Таким образом, понятие «качество жизни» несет в себе социокультурную специфику условий существования человека и зависит от реализации его потребностей, а также от субъективных представлений и оценок собственной жизни. Иначе говоря, образ жизни отдельного человека во многом определяется соотнесением уровня и качества жизни, а также динамикой их изменения и отражает уровень развития как отдельных регионов и слоев населения, так и всего общества в целом.

Степень изученности проблемы. В научной литературе активно исследуется об- раз жизни российской молодежи. Учеными преимущественно изучаются его отдельные структурные компоненты: стили жизни молодежи [2, 15], ее уровень жизни [7, 13], ценностные ориентации $[10,16]$.

Проблема социокультурных параметров и перспектив сложившегося за постсоветский период образа жизни сельской молодежи России - одна из важных проблем. Сегодня сельская молодежь - самая ущемленная в своих правах и свободах социальная группа. Согласно статистике доходной и имущественной дифференциации российского населения, именно она составляет большую долю бедной части российского населения. К тому же сельская молодежь - демографически самая малочисленная и стремительно уменьшающаяся возрастная группа. Из 37,2 миллионов сельских жителей около $11 \%$ молодые люди в возрасте от 15 до 24 лет. Не только из-за недостаточного материально-имущественного обеспечения, но также из-за некачественного общего и профессионального образования, безработицы, низкого уровня развития социальной и культурной инфраструктуры в сельских поселениях молодые жители, как справедливо замечает Л.А. Беляева, «не могут вести образ жизни, соответствующий принятым в обществе образцам» [4, с. 58].

Констатация учеными (Л.И. Беляевой, Л.Т. Волчковой, В.Н. Мининой) «интенсивных процессов поляризации социальной структуры на "богатых" и “бедных" [5, 9], массовых явлений депривации и социальной эксклюзии начала XXI в.» $[1,18,19]$ напрямую затрагивает жителей села как органическую часть социальной структуры. 
Специалисты в области социологии села (П.П. Великий, М.Ю. Морехина, С.А. Никольский) указывают на «интенсивное и диспропорциональное расслоение сельских жителей» в зависимости от сельского образа жизни, от определенного уклада сельскохозяйственного производства и системы сельского расселения в стране $[6,14]$. Социологи постоянно апеллируют к таким компонентам понятия образа жизни, как уровень, качество, уклад, и обязательно в поле их зрения оказывается состояние социокультурной инфраструктуры села.

Эмпирическая база. «Низкое качество жизни, а порой архаичные условия существования жителей села, их оторванность от научно-технического прогресса XXI в., слабая вовлеченность в практики гражданского общества, слабое развитие транспортной инфраструктуры и средств связи» качественно отличают сельский образ жизни от городского $[17$, с. 8$]$.

Абсолютно провальными, с точки зрения функционирования сфер социальной инфраструктуры на селе, можно считать здравоохранение, бытовое обслуживание, газификацию, водоснабжение, автобусное обслуживание.

За 2018 г. закрыта или реструктуризирована 181 больница. Частичная компенсация этого достигается за счет открытия новых амбулаторно-поликлинический организаций (+1844 за период с 2014 по 2018 гг.), но за 2018 г. их число начало снижаться (-72). Также наметилось уменьшение количества ФАПов (-883) за тот же период: с 34436 до 33553 [17]. По количеству врачей на 10000 жителей село значительно отстает от города: 16,2 против 58,8 .

По данным Доклада «О состоянии сельских территорий в Российской Федерации в 2018 году» уровень водоснабжения сельской местности достигает $66,4 \% \quad(61,1 \%$ в 2014 г.), но, как и в любом другом показателе, имеется существенная дифференциация по субъектам Российской Федерации.

Так, например, при общероссийской тенденции к расширению сети учреждений культурно-досугового типа (36,4 тыс. в 2014 г. до 37,8 тыс. в 2018 г.) такой показатель, как «средняя вместимость зрительного зала», равен 155 на 1000 человек. При этом также проявляется ярко выраженная региональная дифференциация: в республиках Северного Кавказа (Чечня, Ингушетия) он колеблется от 15 до 20 мест на 1000 жителей, в то время как в Татарстане, Курской области этот показатель значительно выше - 331-332. Усредненный коэффициент дает более-менее привлекательные цифры, но все же серьезно уступающие городским показателям в 271 зрительское место на 1000 жителей.

Особое место в составе инфраструктуры села занимает спорт и технические возможности для занятия физкультурой. По данным мониторинга, количество спортивных сооружений на 2018 г. составляет 108,6 тыс. единиц (37,8\% от общего числа по стране в целом). Но размещение этих сооружений имеет особый характер дисперсности: чем дальше удаленность населенного пункта от районного центра и чем он малочисленнее, тем менее вероятно развитие и дальнейшая модернизация спортивных объектов (для примера: в х. Чернышев (Грушево-Дубовское сельское поселение Белокалитвинского района Ростовской области) из объектов спортивной инфраструктуры имеются лишь два уличных турника и детская лестница).

Неразвитость объектов досуговой инфраструктуры в сельской местности приводит к тому, что молодежь заменяет конструктивное общение со сверстниками на спонтанные тусовочные связи, частично удовлетворяя существующие потребности в реализации своих потенций.

Кроме того, снижение потребности в квалифицированных специалистах (агроном, зоотехник, ветеринар) вследствие падения уровня сельскохозяйственного производства стало результатом снижения числа работников культурной сферы (библиотекарей), учителей, медицинских работников. Наметилась устойчивая тенденция к оттоку сельской молодежи с мест проживания, несмотря на то, что немногим более половины жителей до 29 лет в целом удовлетворены своей жизнью. Главными причинами являются отсутствие работы (почти 42\% респондентов), проблема с образованием, в том числе из-за отсутствия соответствующих учебных организаций (почти $17 \%$ опрошенных), проблемы с медобслуживанием (12\% респондентов), 
отсутствие возможности проведения досуга (10\% опрошенных) [11].

Как было отмечено, в сравнении с городским образом жизни молодежь, проживающая в сельской местности, сталкивается с целым рядом проблем:

- отсутствием развитой социальной инфраструктуры (прежде всего, в области образования и медицинского обслуживания);

- низкими доходами;

- плохими бытовыми условиями [12].

Ученые подчеркивают, что эксклюзия зависит от крестьянского образа жизни в сложившихся на сегодняшний момент условиях:

- снижения объемов сельскохозяйственного производства;

- неразвитости инфраструктуры;

- преобладания немеханизированного физического труда.

И если зрелое население уже адаптировалось к сельскому образу жизни, устоявшемуся годами, то сельская молодежь находится в состоянии неустойчивого равновесия, испытывая потребность в более полной интеграции в общественную жизнь страны. Однако «низкий уровень жизни и напряженная ситуация на рынке труда порождают социальную исключенность и депривацию» [12, c. 237].

Для обеспечения стабильного развития сельской местности главной задачей является удержание коренного населения на ней. Без качественного изменения социально-экономических условий проживания это вряд ли удастся. На сегодняшний день большинство поселений представляют собой «даже не "агломерации", а рассредоточения индивидуальных жилищ по некой местности, объединенных разве что энергоснабжающей инфраструктурой» [8, с. 124].

Заключение. Развитая инфраструктура дает возможность в перспективе не только приостановить системный коллапс и деградацию российского села, но и запустить качественные изменения как в уровне, так и в качестве жизни его жителей. Именно объекты социально-экономической инфраструктуры и уровень их развития мотивируют сельских жителей (в основном, молодежь) на переезд в город и снижают привлекательность исконно сельских пре- имуществ: близость к природе, возможность иметь свой собственный дом и хозяйство. Необходимы определенный список мер и поступательный подконтрольный характер их исполнения для того, чтобы вернуть селу его истинное предназначение - колыбели русской духовности.

Для этого нужно расширять полномочия глав сельских поселений по части финансовой деятельности, активней привлекать аграрные предприятия для участия в социальной жизни сельской местности, взамен предоставляя им определенные послабления и преференции, расширять список объектов социальной инфраструктуры, проводить пропагандистскую работу среди населения с целью вовлечения его в культурную, духовную, спортивную жизнь территории проживания. Ведь на сегодняшний день только построить, модернизировать объекты инфраструктуры недостаточно: низкая социальная защищенность сельской молодежи способна не только влиять на ее общее социальное самочувствие, но и привести к снижению уровня потребностей и притязаний среди ее представителей.

\section{Литература}

1. Абрахамсон П. Социальная эксклюзия и бедность // Общественные науки и современность. - 2001. - №2.

2. Барышева Е.И. Стиль жизни молодежи как отражение содержания субъективного жизненного пространства личности // Вестник Костромского государственного университета. Серия: Педагогика. Психология. Социокинетика. - 2016. - Т. 22. - №2. - С. 252-257.

3. Беляева Л. А. Уровень и качество жизни. Проблемы измерения и интерпретации // Социологические исследования. - 2009. №1. - С. 33 .

4. Беляева Л.А. Социальная стратификация и бедность в регионах России // Coцис. - 2006. - №9. - С. 58.

5. Беляева Л. И. Региональная и поселенческая разнородность уровня жизни населения России // Мир России. - 2006. - №2.

6. Великий П.П., Морехина М.Ю. Адаптивный потенциал сельского социума // Coцис. - 2004. - №12.

7. Виноградова E. С. Роль молодежи в повышении уровня жизни в регионе // Научный 
форум: Экономика и менеджмент. Сборник статей по материалам XVIII международной научно-практической конференции. 2018. - C. 27-30.

8. Виноградская О.Я. Онтологические основания переезда горожан в деревню // Крестьяноведение. - 2018. - Т. 3. - №4. C. 127.

9. Волчкова Л. Т., Минина В.Н. Стратегия социологического исследования бедности // Социс. - 1999. - №1.

10. Капустина A.H. Теоретический и эмпирический анализ изучения базовых ценностей и ценностных ориентаций представителей молодежи // Институт психологии Российской академии наук. Социальная и экономическая психология. - 2017. - Т.2. №3. - С. 39-61.

11. Калачикова О.Н., Будилов А.П. Отток молодежи из сельской местности: мотивы и возможности регулирования // Социальное пространство. - 2018. - №3 (15). - С. 1-9.

12. Кужелев М.А. Понятие социальной эксклюзии и образа жизни молодежи в социологическом знании // Государственное и муниципальное управление. Ученые записки. - 2019. - №3. - С. 234-238.

13. Муравлева В.В. Уровень жизни населения: сравнительный анализ и особенности потребления молодыми гражданами // Вестник ОрелГИЭТ. — 2017. — №3 (41). C. 159-166.

14. Никольский С. А. Аграрный курс России. - М., 2003.

15. Фадеева И.М., Сысуева В.И. Стиль жизни молодежи как показатель воспроизводства среднего класса региона // Регионология. — 2016. — №3 (96). — С. 123-136.

16. Хазова С.А., Крылова М.А. Ценностные ориентации, копинг-стратегии и стиль жизни современной молодежи // Ананьевские чтения - 2017. Преемственность в психологической науке: В. М. Бехтерев, Б. Г. Ананьев, Б. Ф. Ломов. Материалы традиционной международной научной конференции. 2017. - С. 436-437.

17. Шевелкина К.Л., Серова Е.В. О состоянии сельских территорий в Российской Федерации в 2018 году. Ежегодный доклад по результатам мониторинга: науч. изд. М.: ФГБНУ «Росинформагротех», 2020. Вып. 6. - 224 с.
18. Paugam $S$. Poverty and Social Disqualification: Analysis of Cumulative Social Disadvantage in Europe // Journal of European Social Policy. - 1996. - Vol. 6. - №4.

19. Rutter M., Madge N. Cycles of Disadvantage: A Review of Research. - L.: Heinemann, 1976.

\section{References}

1. Abrahamson P. Social'naja jekskljuzija i bednost' [Social exclusivity and poverty] // Obshhestvennye nauki i sovremennost' [Social Sciences and Modernity]. — 2001. - №2.

2. Barysheva E.I. Stil' zhizni molodezhi kak otrazhenie soderzhanija subektivnogo zhiznennogo prostranstva lichnosti [The lifestyle of youth as a reflection of the content of the subjective living space of the individual] // Vestnik Kostromskogo gosudarstvennogo universiteta. Serija: Pedagogika. Psihologija. Sociokinetika [Bulletin of the Kostroma State University. Series: Pedagogy. Psychology. Sociogenetic]. - 2016. - Vol. 22. 一 №2. Pp. 252-257.

3. Beljaeva L.A. Uroven' i kachestvo zhizni. Problemy izmerenija i interpretacii [The level and quality of life. Problems of measurement and interpretation] // Sociologicheskie issledovanija [Sociological researches]. — 2009. №1. - P. 33.

4. Beljaeva L.A. Social'naja stratifikacija i bednost' v regionah Rossii [Social stratification and poverty in the regions of Russia] // Socis. 2006. - №9. - P. 58.

5. Beljaeva L.I. Regional'naja i poselencheskaja raznorodnost' urovnja zhizni naselenija Rossii [Regional and settlement heterogeneity of the standard of living of the population of Russia] // Mir Rossii [The world of Russia]. - 2006. - №2.

6. Velikij P.P., Morehina M. Ju. Adaptivnyj potencial sel'skogo sociuma [Adaptive potential of rural society] // Socis. — 2004. — №12.

7. Vinogradova E.S. Rol' molodezhi v povyshenii urovnja zhizni $v$ regione [The role of youth in raising the standard of living in the region] // Nauchnyj forum: Jekonomika i menedzhment. Sbornik statej po materialam XVIII mezhdunarodnoj nauchno-prakticheskoj konferencii [Scientific Forum: Economics and Management. Collection of articles based on the materials of 
the XVIII International scientific and practical conference]. - 2018. - Pp. 27-30.

8. Vinogradskaja O. Ja. Ontologicheskie osnovanija pereezda gorozhan $\mathrm{v}$ derevnju [Ontological grounds for moving citizens to the village] // Krest'janovedenie. - 2018. - Vol.3. №4. - P. 127.

9. Volchkova L.T., Minina V.N. Strategija sociologicheskogo issledovanija bednosti [Strategy of sociological research of poverty] // Socis. - 1999. - №1.

10. Kapustina A.N. Teoreticheskij i jempiricheskij analiz izuchenija bazovyh cennostej i cennostnyh orientacij predstavitelej molodezhi [Theoretical and empirical analysis of the study of basic values and value orientations of youth representatives] // Institut psihologii Rossijskoj akademii nauk. Social'naja i jekonomicheskaja psihologija [Institute of Psychology of the Russian Academy of Sciences. Social and economic psychology]. — 2017. - Vol.2. — №3. Pp. 39-61.

11. Kalachikova O.N., Budilov A.P. Ottok molodezhi iz sel'skoj mestnosti: motivy i vozmozhnosti regulirovanija [Outflow of youth from rural areas: motives and opportunities for regulation] // Social'noe prostranstvo [Social space]. - 2018. — №3 (15). — Pp. 1-9.

12. Kuzhelev M.A. Ponjatie social'noj jekskljuzii i obraza zhizni molodezhi v sociologicheskom znanii [The concept of social exclusion and the way of life of young people in sociological knowledge] // Gosudarstvennoe i municipal'noe upravlenie. Uchenye zapiski [State and Municipal management. Scientific notes]. - 2019. - №3. - Pp. 234-238.

13. Muravleva V.V. Uroven' zhizni naselenija: sravnitel'nyj analiz i osobennosti potreblenija molodymi grazhdanami [The standard of living of the population: a comparative analysis and the consumption patterns of young people] // Vestnik OrelGIJeT. - 2017. - №3 (41). - Pp. 159-166.

14. Nikol'skij S.A. Agrarnyj kurs Rossii [Agrarian policy of Russia]. - Moscow, 2003.

15. Fadeeva I.M., Sysueva V.I. Stil' zhizni molodezhi kak pokazatel' vosproizvodstva srednego klassa regiona [The lifestyle of young people as an indicator of reproduction of the middle class in the region] // Regionologija [Regionology]. — 2016. — №3 (96). — Pp. 123-136.

16. Hazova S. A., Krylova M.A. Cennostnye orientacii, koping-strategii i stil' zhizni sovremennoj molodezhi [Value orientations, coping strategies and lifestyle of modern youth] // Anan'evskie chtenija - 2017. Preemstvennost' v psihologicheskoj nauke: V.M. Behterev, B.G. Anan'ev, B.F. Lomov. Materialy tradicionnoj mezhdunarodnoj nauchnoj konferencii [Ananiev Readings - 2017. Continuity in psychological science: V.M. Bekhterev, B. G. Ananyev, B.F. Lomov. Materials of the traditional international scientific conference]. - 2017. Pp. 436-437.

17. Shevelkina K.L., Serova E.V. O sostojanii sel'skih territorij v Rossijskoj Federacii v 2018 godu. Ezhegodnyj doklad po rezul'tatam monitoringa: nauch. izd. [On the state of rural territories in the Russian Federation in 2018. Annual report on the results of monitoring: scientific ed.]. - Moscow: FGBNU «Rosinformagroteh», 2020. - Issue 6. - $224 \mathrm{p}$.

18. Paugam S. Poverty and Social Disqualification: Analysis of Cumulative Social Disadvantage in Europe // Journal of European Social Policy. - 1996. - Vol. 6. - №4.

19. Rutter M., Madge N. Cycles of Disadvantage: A Review of Research. - L.: Heinemann, 1976. 


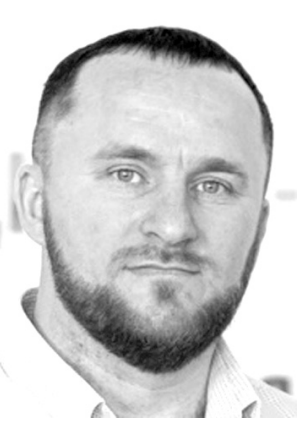

Кужелев Максим Александрович - старший преподаватель кафедры «Мировые языки и культуры» Донского государственного технического университета, аспирант кафедры «Социальные и гуманитарные науки» Южно-Российского государственного политехнического университета (НПИ) имени М.И. Платова.

Kuzhelev Maxim Aleksandrovich - Senior lecturer, Department «World languages and cultures» Don State Technical University, Post-graduate student, Department «Social and Humanitarian sciences», Platov South Russian State Polytechnic University (NPI).

344003, г. Ростов-на-Дону, пл. Гагарина, 1

1 Gagarina sq., 344003, Rostov-on-Don, Russia

E-mail:kuzhelev@hotmail.com 